\title{
Reorganizing the Use of Theory in Health Promotion: Lessons from Ecology
}

Kevin M Cummins 1,2,3* $^{2}$

${ }^{1}$ Joint Doctoral Program in Interdisciplinary Research on Substance Use, Division of Infectious Diseases and Global Public Health, Department of Medicine, University of California San Diego, La Jolla, CA, USA. ${ }^{2}$ School of Social Work, San Diego State University, San Diego, CA, USA

${ }^{3}$ Departments of Psychology and Psychiatry, University of California San Diego, La Jolla, CA, USA.

* Correspondence:

Kevin M Cummins

Department of Psychology

University of California San Diego

9500 Gilman Drive

La Jolla, CA 92093-0109

858.295.2763

kcummins@ucsd.edu

ORCID: 0000-0003-1982-7836

\section{Declarations of Interest}

The author declares that the research was conducted in the absence of any commercial or financial relationships that could be construed as a potential conflict of interest.

\section{Author Contributions}

KMC conceived and developed the manuscript.

\section{Funding}

Research support from the School of Social Work at San Diego State University through the Joint Doctoral Program in Interdisciplinary Research on Substance Use was critical for the completion of this work.

\section{Word Count}

Body: 6005 
Abstract: 205

Lay Summary: 109

Tables: 2

Figure: 1 


\begin{abstract}
The discipline of health promotion is currently struggling to attain networks of strong and exclusively accepted theories. Other scientific disciplines, such as ecology, have also experienced challenges in developing genuine scientific theory that organizes the field and facilitates powerful engineering tools for interventions. Ecology is similar to health promotion in that the units of study are not exchangeable and include processes with large numbers of interacting determinants. Additionally, both ecology and health promotion have limited access to system-wide experimentation. The early dialogue within ecology regarding the benefits of theory parallels discourse found in the health promotion literature. However, ecology has taken a different route in its approach to theory. Ecology's progress provides justification for expanding health promotion's vocabulary to improve the delineation and characterization of its conceptual devices. It is posited that an expanded lexicon will facilitate improved understanding of related methodological recommendations and underscore that suggested benefits of theory are achieved when using wellformed, severely tested theories. Ecology's history suggests paratheoretical approaches can be successful in realms of inquiry that are resistant to theory formation, such as health promotion. Ultimately, health promotion, and public health more broadly, can enhance its theory-aligned strengths by focusing its effort on modeling and developing general bounding principles. Keywords: health promotion, health behavior, paratheoretical research, abductive inference, exploratory research, scientific representation, complex adaptive systems, hierarchy theory
\end{abstract}

\title{
Lay Summary
}

Researchers and practitioners strive to use theory in the hopes of improving population health. Evidence that supports the use of theory in practice has been mixed. This may be due to the types 
of theory being utilized by the field. The field of ecology experienced a similar challenge with its theories. In response, ecology developed different approaches to framing research that were both more certain and generalizable than are used in public health while also recognizing the complex nature of ecology. Human behavior is similarly complex. Further parallels between ecology and health promotion are outlined. Application of alternative approaches to framing research and practice in public health are suggested. 


\section{Introduction}

Health behavior researchers have presented strong positions in support of the use of theory in health promotion (HP) research and practice (Albada, Ausems, Bensing, \& van Dulmen, 2009; Datta \& Petticrew, 2013; Glanz \& Bishop, 2010; Lippke \& Ziegelmann, 2008; Noar, Benac, \& Harris, 2007; Michie, Johnston, Francis, Hardeman, \& Eccles, 2008). Authors have stated that grounding evidence-based interventions in theory is necessary to describe and act on the determinants of health outcomes (Bartholomew et al., 2016). In contrast, there is debate over the benefits of theory in HP (Hagger \& Weed, 2019). Support from recent meta-analytic investigations evaluating the benefits of theory is equivocal at best (Prestwich et al., 2014; Lock, Post, Dollman, \& Parfitt, 2020; Michie, West, Campbell, Brown, \& Gainforth, 2014). Unfortunately, much of the body of work evaluating theory has largely been based on cross-study comparisons.

Consequently, there are multiple conceptual and methodological limits to the field's ability to assess theory's efficacy and contributions to the advancement of health promotion as a whole (Cummins, Pitpitan, Reed, Zuniga, \& Brown, 2021). These issues include confounding of study quality with the use of theory (Noar et al., 2007) and the conflation of models with theory within evaluation studies (Cummins et al., 2021). Another well-recognized issue is that many studies reporting to have used theory may have actually had little theoretical grounding (Painter, Borba, Hynes, Mays, \& Glanz, 2008; Prestwich et al., 2014; Cummins et al., 2021) invoking theory in a manuscript does not ensure theory was rigorously applied. A newly recognized issue is the lack of discrimination between accepted theory and a proposed theory (see §ldentifying Theory Status: Why Should Theories be Differentiated?).

The greatest challenge to theory evaluation and development is the sparsity of original studies that were designed specifically to estimate the causal effect of theory utilization (cf. Reback, 


\section{Theory in Health Promotion}

Fletcher, Shoptaw, \& Mansergh, 2015). Most evaluations lean heavily on the extant literature where confounding cannot easily be disentangled between studies integrating scientific representations described as theory and those that are based on a comprehensive understanding of the domain of study; this is because health promotion (HP) uses theories, models, and frameworks to store its knowledge about health behaviors (Brug, Oenema, \& Ferreira, 2005). It is difficult to use knowledge derived from the health behavior literature as a basis for a study without being influenced by theory. This problem is a particularly potent issue when recommendations are to use theory mainly as a list of mediators to be selected from and incorporated into interventions and study designs. This is a prominent description of how to leverage theories intervention (Crosby, Kegler, \& DiClemente, 2009; Glanz, Rimer, \& Viswanath, 2015; Michie \& Prestwich, 2010; ; Nigg, Allegrante, \& Ory, 2002; Noar \& Zimmerman, 2005; Michie, West, Campbell, Brown, \& Gainforth, 2014).

The mostly unacknowledged but dominating problem for the field is inconsistent conceptual discrimination between, and weakly differentiated treatment of, theories and models. Although many health behavior researchers have noted that the two conceptual devices are distinct (Cummins et al. 2020), there has been little resolution regarding their differences in terms of their uses and benefits. Contrasts between models and theory may be underappreciated because HP as a field might not hold conceptual devices that possess the features of genuine archetypal theory (see Cummins et al., 2021; Glanz, Rimer, \& Viswanath, 2015). Alternatively, HP may not be leveraging the unique features of theory where theories exist. Such features include the production of deductively derived novel predictions. This is not a benefit we should expect from a list of potential mediators. A misalignment between the suggested capacities of health promotion's cognitive devices (i.e., frameworks, models, theory) and their actual functions may partially explain the 
absence of a conclusive body of evidence in support of theory in HP. The main reason evidence to support the use of theory is weak is that HP has few established theories to leverage.

Within this paper, the scientific representations (i.e., frameworks, models, theory) that are the subject of discussions of theory in much of the HP literature will be referred to as conceptual devices. Each type of conceptual device has different characteristics and functionality. The function of authentic hypothetico-deductive theory is richer than an inventory of determinants (Boniolo, 2007; Cummins et al., 2021). In addition to producing deductively derived novel predictions, key features of theory are falsifiability and demarcation of the class of phenomena that the theory applies (Cummins et al., 2021). Furthermore, theories carry some truth value regarding how a class of phenomena operates, whereas models are structures that function as fictive representations of some aspects of the system of interest (Boniolo, 2007). They are constructed with the intent to capture abstracted similarities with the real system (Godfrey-Smith, 2009). Models will not capture all of the features of the system being studied, so researchers apply judgment to balance realism, generalizability, and precision (Levins, 1966). There is no single correct model, only various model options where each provides different benefits. A full explication of the properties of each type of cognitive device is beyond the scope of this current paper. The reader is directed to a presentation of various views and categorizations of models by Harré (2004) and desiderata of theories by Cummins et al. (2021).

$\mathrm{HP}$ is not the only discipline to struggle with efforts to improve the theoretical grounding of its research and practice when theories with the features of archetypal theory like that achieved in some areas of physics are sparse. Contrasting with, and leveraging lessons from, other fields that have struggled to obtain evidentiary support for theory and achieve a network of reliable archetypal 
hypothetico-deductive theories can provide possible roadmaps for HP to advance even in the absence of theory.

Ecology is one such discipline. In many respects, ecology parallels HP. Both disciplines study complex adaptive systems that are driven by many causally reciprocating determinants and nonlinear responses. Over the last two decades, some HP researchers have recognized that current health behavior theories and approaches do not adequately incorporate complex dynamics (Keshavarz Mohammadi, 2019). This recognition has resulted in the proposal to incorporate complexity theory into HP research and practice (Green, 2006; Resnicow \& Page, 2008; Keshavarz Mohammadi, 2019). Such proposals have not yet translated into widespread change in the way that health behavior research and practice is framed. Compared to HP, the field of ecology has a much more thorough recognition of the consequences of working with complex adaptive systems (CAS) (Maris et al., 2018). In part, this may be due to the conflation of models and theory and the different and contingent benefits of using different types of cognitive devices. Current conventions promoting the use of theory provide some constraints on HP researchers for incorporating complexity because most of the cognitive devices currently identified as theory do not address features of CAS. The acceptance of alternative approaches and perspectives on the use of cognitive devices (i.e., theory) can foster greater incorporation of models into research and practice that reflect the features of CAS as has occurred in ecology (Schlueter et al., 2012; Ryan, Ludwig, \& Mcalpine, 2007; Levin, 1998; Levin, 1999; Levin, 2005; Railsback, 2001).

Another similarity between ecology and HP is that both fields are capable of limited experimental interventions but also rely on observational evidence where barriers to experimentation are substantial, such as at large scales (i.e., whole populations). Units of observation in both fields are rarely exchangeable, in that the idiosyncratic histories of each unit 
mean that they cannot be swapped out without the expectation that the system trajectories will change in important ways; a chemist can swap out water molecules and expect the same dynamics, whereas health promotion researchers cannot say the same about swapping out people. At the scale of inquiry, every unit is unique in important ways in both ecology and health promotion. These parallels make the similarities between ecology's historic dialogue regarding the role of theory valuable to consider in the context of HP's current literature on theory.

Although HP researchers have promoted the use of theory as a key mechanism for the advancement of the field (Krieger \& Zierler, 1996; Leviton, 2017; Glanz \& Bishop, 2010), health promotion can advance in the absence of genuine theory. This paper reviews the relevant theoryrelated history of ecology to emphasize its parallels with HP and explain the motivations behind ecology's diverging approach to theory. The paper concludes by outlining ecology-inspired alternative pathways for scientific advancement in the absence of reliable and well-formed theory.

\section{History of Theory in Ecology: What Can Ecology Teach Us About Making Scientific Progress When}

\section{Theory Is Elusive?}

The history of ecology provides lessons and opportunities for HP. The tension within ecology regarding its theoretical development has been previously outlined by Mclntosh (McIntosh, 1986). The five relevant historical themes from this work consist of (1) ambiguous lexical and conceptual treatment of conceptual devices, (2) the substantial industry of mathematical modeling of ecological processes, (3) field ecologists' skepticism of theoretical work, (4) recognition of the scarcity of ingrained theory (i.e., established, tested, and adopted theory), and (5) ecologists' circumspection of their ability, or need, to achieve idealized physics-like theoretical matrices to buoy and direct the field. The first theme has also been mentioned within the field of HP, but its implications have rarely been elaborated (c.f. Cummins et al., 2021). An equal counterpart to the 
second theme is generally absent in HP (cf. Homer \& Hirsch, 2006; Levy, Bauer, \& Lee, 2006; Smit et al., 2011), and the third theme is similar to some practitioners' attitudes in HP. The last two themes on scarcity and circumspection, however, contrast with the dominant attitudes in HP. Elaboration of these five themes and their relationship to HP is included below.

\section{Theme 1: Addressing Theory-related Terminological and Conceptual Ambiguity}

It has been suggested that theory, as it is construed in the natural sciences, may not be attainable in the social sciences (Flyvbjerg, 2001). Consequentially, it might be counterproductive even to use the word theory in social sciences (Flyvbjerg, 2001). Ecology's experience indicates that HP may need an alternative to this suggestion because HP may be unlikely to eliminate, or even reform, the theory-related terminology in current use (Hodges, 2008). Instead, the field can benefit from extending its vocabulary to communicate unambiguously and distinguish types of conceptual devices and their evidentiary status.

Murray described the barriers to the development of ecological theory as an attitude that biological systems are too complex, the avoidance of imagination initiated deductive-nomothetic approaches, and the conflation of conceptual device types (Murray, 2001). Ecologists have had differing views, but there is no disagreement that the sparsity of theory has slowed progress, as has the lack of a consistent, coherent, and lucid conception of theory (McIntosh, 1986). McIntosh concludes that this was in part due to an ambiguous and imprecise lexicon related to the topic (Mclntosh, 1986). As such, McIntosh's conclusion regarding the conceptualization of theory is eminently relevant to HP. Fortunately, this issue is surmountable by adopting a more descriptive vocabulary that distinguishes among conceptual device types and their evidentiary status. To motivate and clarify the discussion, a tentative taxonomy of conceptual devices is presented in Table 1. A key aspect of this taxonomy is that it extends the fields' vocabulary. A key consequence 
of adopting a refined taxonomy would be the heightened distinction between proposed and ingrained theories (see Table 1). Only ingrained theories are conceptual devices that a field can rely on as if they were exclusively correct.

\section{--- Table 1 about here ---}

In both ecology and HP, the term theory can refer to the investigation and communication of abstract knowledge (Gorelick, 2011; Krebs, 2017; Marquet et al., 2014). In some contexts, ecologists describe theory as a scheme or system of ideas that accounts for a group of phenomena (Harper, 1980). This is consistent with an interdisciplinary perspective on theory (Cummins et al. 2020). Ecologists have also used the term to include hypothesized explanations at various scales (Smith, 1976). This is similar to the psychological sciences (Gigerenzer, 2011). In ecology, theory can also refer to all academic activities involving mathematical or computational modeling (Kolasa, 2011). In many cases, the specific intent of the communication that refers to theory can be implied by its context when the reader is cognizant of the different meanings that theory-related vocabulary can take on (Hodges, 2008). However, even champions of theoretical ecology were unsure of the field's definition (Harper, 1980; Mclntosh, 1980). The important point for the current paper is that lexical ambiguity related to theory in ecology was common. This was seen as muddying expectations about theory (Scheiner, 2012) in a way that is similar to what is occurring in HP. To this point, some HP researchers have also recognized the terminological and conceptual blurring between models and theory (Nilsen, 2015; Bartholomew \& Mullen, 2011).

Conflating models and theory can impact the attitudes of practitioners toward theory. Within ecology, wildlife managers (i.e., practitioners) did not see ecological theory as providing 
reliable tools and predictions (Romesburg, 1981). Indeed, hunches and common sense were seen as equal to theory in the design of interventions (Romesburg, 1981). However, this view was based on the terminological usage of theory as being synonymous with unparameterized models that are unconnected to well-formed authentic theory. Models and theory are very different (Boniolo, 2007). Models are wrong; ingrained theories are considered at least approximately correct. While there are HP researchers that recognized the critical distinction between theories and models (Nilsen, 2015), ecologists have had a greater appreciation for the importance of this discrimination. Identifying Theory Status: Why Should Theories be Differentiated?

The identification of the developmental status of theory has been recommended in ecology (Kolasa, 2011; Pickett, Kolasa, \& Jones, 2010). Applying a nomenclature communicating the status requires the recognition that theories vary in their merit. This is important because we should have expectations commensurate with a theory's status, and our research programs can be optimized to focus on questions that are most appropriate for the stage of a theory's development and evaluation (see Pickett, Kolasa, \& Jones, 2010).

Strong ingrained theory needs no salesperson. Geoscientists will just use the Theory of Plate Tectonics (Zheng, 2018; Mulyukova \& Bercovici, 2019). Global positioning systems engineers will just use the Theory of Relativity (Ashby, 2003). HP would benefit from using the posture of the physical sciences, where ingrained theory is treated as the conceptual device that can hold the greatest truth value and can be directly used for the engineering of interventions.

Where there have been calls for interventionists to increase the use of theory in public health, there have been responses that theory is not seen as useful (Rothman, 2004). Practitioners' concerns about theory can be partially attributed to holding expectations that any theory, of any status, will suffice. Making the distinction between a proposed theory and one which is considered 
substantiated, considered uncontested, and interwoven into the discipline (i.e., ingrained theory) will have two benefits if recommendations for practitioner utilization are limited to ingrained theory. This will improve intervention practice and improve practitioners' trust in theory.

Whereas ecology has recognized the importance of reserving credence for ingrained theories with high verisimilitude (Smith, 1976), HP provides a potentially confusing view of theory. Interventionists have even cited theory as weak on evidentiary support (Campbell et al., 2000). Adopting an expanded taxonomy could potentially help reconcile these cross-disciplinary discrepancies and add clarity to recommendations made to practitioners. Poorly formed proposed theory should be viewed with suspicion, whereas ingrained theory should be promoted as a basis for intervention engineering.

\section{Theme 2: The Mathematical Ecology - Modeling Without Theory}

Mathematical modeling has been employed extensively in ecology. This modeling effort comprises much of the work often referred to as theoretical ecology, particularly in the context of inquiry into population dynamics. Some of the related work has illuminated the potential for complex dynamics arising from systems with simple structures, such as idealized interactions between two species. Lotka-Volterra models demonstrated how competing species could exclude each other from a location, where they would otherwise occur in the absence of their competitor (Wangersky, 1978). Simple models for predator-prey interactions also demonstrated situations in which interacting populations could result in stable dynamics or extinction (May \& Oster, 1976; May, 1976). The modeling required ecologists to be explicit and quantitative in their assumptions. Consequently, it provided checks on cognitive errors regarding the results of ecological interactions, provided machinery for making quantitative predictions, and focused ecologists' thinking about substantive problems (Christiansen \& Fenchel, 2012). Even though modeling helped ecologists think 
and orient, the foundational deterministic modeling was seen as a dubious approach to quantitative prediction of actual populations (Oster, 1981; Smith, 1952).

--- Figure 1 About Here ---

Where the early modeling was pressed to predict real populations, such as small mammal population cycles, there were a series of failures (Sagoff, 2016; Chitty, 1996). This was, in part, attributed to the models reflecting an incorrect explanation for the observed dynamics (Boonstra, Krebs, \& Stenseth, 1998; Chitty, 1996; Sagoff, 2016). The models were not, nor are constituent of, ingrained theory. On the other hand, there have been modeling successes. Modeling developed closely with observational data has been useful in managing ecological resources, like fisheries and threatened species (Akçakaya, Franklin, Syphard, \& Stephenson, 2005; Beamish \& Rothschild, 2009; Converse \& Moore, 2013; Hilborn \& Ovando, 2014; Lawson, Regan, Zedler, \& Franklin, 2012). Models used to inform ecological interventions are commonly phenomenological models (see Figure 1). Ecologists know these models are not derived from theories and expect commensurately less of them (Schnute \& Richards, 2001). Natural resource managers assume the models provide better service to decision making than deliberating without the quantitative analysis of their assumptions. However, these phenomenological models are recognized as imperfect, and their application benefits from empirical monitoring, model adaptation, and substantial caution. Patterns generated by models can also help identify possible mechanisms behind phenomena (Collie, Richardson, \& Steele, 2004), which in turn could ultimately lead to the development of theories. The perceived danger has been that the models themselves could become reified (Krebs, 2017). Ecology has wrestled with models that are disconnected from strong empirical evaluation 
being mistaken for representations of reality that are adequate for use in prediction, control, and understanding (Romesburg, 1981; Kolasa, 2011; Yodzis, 1989). To some extent, plainly

oversimplified models were expected to operate like theory. Subsequent expositions of expanded families of related ecological models provided clues as to how inappropriate the models could be as intervention instruments. The early models have been expanded to incorporate stochasticity and spatial dynamics. As an example, when models predicting competitive exclusion (a core concept in ecology) incorporated these extensions, the coexistence of competing species became a stable outcome (Lehman \& Tilman, 1997). This result about competitive exclusion changes our basic understanding, to the extent that the models teach us about the world. Quantitative prediction was also affected by the extensions. For example, predicted incidence rates substantially change in infectious disease models when stochasticity is introduced (Renshaw, 1993). These provide important lessons for HP. Models that are unlinked to theory can help the field progress.

\section{Theme 3 and 4: Skeptical Ecologists - Some Models Are Dangerous}

Ecologists had been divided into two camps (Haller, 2014). One focused on creating and analyzing mathematical models. The other conducted empirical work and harbored some skepticism of the modeling (MacArthur, 1962; Mclntosh, 1986). It was considered "fantasy" to believe that the behaviors observed in foundational deterministic ecological models might be observed in the field (Renshaw, 1993, p. 4;). The other side acknowledged that much of the research churn was based on unrealistically simplified models while noting that mathematical analysis of the properties of sleek models is greatly useful in supporting the understanding of more nuanced models (May, 1981). Even modeling thought leaders warned that reliance on models as a basis of biological knowledge about topics under investigation would be problematic (Cody \& Diamond, 1975). Because the models were not derived from ingrained theory, they were not seen 
as the repository of the field's knowledge (Yodzis, 1989). The body of observational and experimental work was seen as the core source of the field's knowledge. In many cases, the models were simply tools to help leverage other sources of knowledge or to help guide the research process. The simplified models of mathematical ecology might appear to present key building blocks of general theory, until it is recognized that the models "simply do not hold" (Slobodkin, 1965, p. 348). Ecological models were not intended to be the field's repository of the field's knowledge (Romesburg, 1981) in a way that mirrors the use of cognitive devices in HP.

Ecologists' skepticism about obtaining relevant theories does not arise from a lack of recognition in the benefits of theory (Grime, 2007; Scheiner \& Willig, 2011a; Haller, 2014). Indeed, some ecologists had physics-envy. The skepticism resulted from ecologists' pallet of cognitive devices' inability to function as a network of well-formed theories (McIntosh, 1986). In summary, the lessons for HP are: (1) a gap between the perceived promises of theory and what individual cognitive devices actually provide can catalyze skepticism, and (2) phenomenological modeling has benefits, just not the same as ingrained theory. The expectation gap can be narrowed by presenting benefits as being contingent on the type and status of the cognitive device being used and promoting only models that can be characterized regarding their generality, precision, and realism for application to health interventions.

\section{Theme 5: Dismissed Need and Circumspect Hope - Progress Without Theory}

It can be seen as iconoclastic to question the role of theory in HP, whereas skepticism in ecology was open and multifaceted. Not only was the conflation of models and theory a skepticism generator, the need for theory itself was even questioned. Rather than being seen as spurring useful empirical work, some considered theoretical work a distraction. Dayton wrote, "Ecology often seems dominated by theoretical bandwagons driven by charismatic mathematicians, lost to 
the realization that good ecology rests on a foundation of natural history and progresses by use of proper scientific methods" (Dayton, 1980, p. 156). Theory was not required for advancing knowledge. Although Margalef (Margalef, 1963) stated that ecology was extremely poor in unifying principles, progress and application have been possible, as demonstrated through experimentinformed interventions and development of intervention principles (Braysher, Buckmaster, Saunders, \& Krebs, 2012). Yes, the field lacked the blueprint for the core features structuring ecosystems. Prediction and control were also costlier without theory. Cohesion in the field was limited. Progress was still possible.

Perhaps, theory cannot always be obtained. This may be a result of the complexity of the systems under investigation. Ecologists typically study middle-number systems (Allen \& Starr, 2017). Its elements and influences are too numerous to enumerate in an idiographic approach, but contextual influences often dominate the system (Pickett, Kolasa, \& Jones, 2010). Relative to the scales of determinants, its elements are too few to result in smoothed average signals to investigate. The occurrence of equilibrium states may be rare, as determinants are heterogeneous and unstable. The effect of heterogeneous histories on units of analysis may be the strongest signal on the outcome of interest. Ecosystems exist in unique states in ways that affect future states (Jørgensen et al., 2011). The slew of challenges for developing explanations and predictions in ecology is further frustrated by investigations of phenomena that are the result of processes operating at differing temporal and spatial scales (Levin, 1992). This is why there was some skepticism of achieving broad coverage of theory in ecology. In comparison, there may be more optimism among some HP researchers (Hagger \& Weed, 2019). However, HP often works with middle-number CAS and faces similar challenges as ecology. As a consequence, well-formed theory may be elusive in both fields. 


\section{Discussion}

\section{How Do Lessons from Ecology Map to Health Promotion?}

Ecology's modeling industry did not create disciplinary cohesion. The discipline resembled "an amorphous, post-modern hotel and rabbit warren with separate entrances, corridors and rooms that safely accommodate the irreconcilable" (Grime, 2007, p. 227). This state existed in ecology despite the experimental literature commonly invoking theory (Kolasa, 2011; Scheiner, 2013). Ecology and HP are in analogous situations - the underlying issue appears to be a desire to use theory whilst broad ingrained theory is scarce. Ecology's history offers multiple strategies that HP can use as a response to this situation (Table 2).

The first is to inaugurate new traditions of method and conceptualization that organize the field. HP has done this before with its movement toward socio-ecological approaches (Hovell, Wahlgren, \& Adams, 2009; Sallis, Owen, \& Fisher, 2015). Similarly, ecology has also shown how there can be paradigm adjustments without a new content-based theory (Chesson \& Case, 1986; Kolasa, 2011). For example, hierarchy theory lays out how researchers may approach ecosystem processes operating at different scales without making specific predictions about any specific ecosystem (Allen \& Starr, 2017).

Neither field may be able to anchor itself in archetypal theory, as some physical sciences have, but it can still organize itself using conceptual frameworks (Burkholder, Cox, Crawford, \& Hitchcock, 2019; Pickett, Kolasa, \& Jones, 2010). Where theory is sparse, integration of various forms of knowledge, modeling, and abductive research programs has been successful in addressing important ecological questions (Table 2; National Research Council, 1986; Shrader-Frechette, 2008). Accepting the use of theory-free conceptual frameworks is the first approach that HP can adopt (Burkholder, Cox, Crawford, \& Hitchcock, 2019). 
A second approach is to build bounding conceptual devices to help guide research (Table 2). Two examples are the work lead by Scheiner and Willig and the other by Jørgensen (Jørgensen et al., 2011; Scheiner \& Willig, 2011b). The bounding conceptual devices are lists of fundamental principles of broad disciplinary scope, which constrain subtending conceptual devices (Scheiner \& Willig, 2011a). In this scheme, theories with a narrower scope, such as the Theory of Island Biogeography, are nested as constituent theories within the fundamental principles. The constituent conceptual devices must conform to the principles. The intent has been to provide conceptual scaffolding for the whole of the discipline, so the organizing and cohesive benefits of theory can be obtained. To be clear, these general "theories" are a "list of fundamental principles" and a set of "basic principles" that can be combined to predict bounds on ecosystem processes and patterns (Scheiner \& Willig, 2011a, p. 4; Jørgensen and Fath, 2004). These are not archetypal theories as described in Cummins et al. (2020).

These principles are presented in conjunction with other assumptions, definitions, logical or causal structures, and explication of the domain of applicability. Multiple processes are expected to be nested within these bounding conceptual devices. It is the constituent conceptual devices that are expected to provide precise structures to be instantiated in individual predictive models. Even laws in ecology would occur at the constituent level (Scheiner \& Willig, 2011a). Examples of principles of ecology include: (1) organisms are distributed in space and time in a heterogeneous manner, and (2) birth and death rates are a consequence of interactions with the abiotic and biotic environment (Scheiner \& Willig, 2011a). The proponents of these bounding conceptual devices 
recognize these as basic axioms related to population processes. In isolation, the set of principles do not provide much service to a practitioner. Their careful formal listing helps hone the science and ensure that construction and evaluation of constituent conceptual devices reflect these disciplinewide principles.

Even contemporary ecologists at the forefront of "theoretical" developments are not optimistic about achieving well-formed archetypal theories. Instead, their hope is for unification through conceptual devices that bound subtending research and theory. HP may benefit from taking a similar posture. In some respects, health behavior researchers have begun to adopt this approach. For example, the Theoretical Domains Framework (TDF) can be construed as providing bounds for conceptualizing system of interest (Michie et al., 2005). The TDF inventories, synthesizes, and catalogs constructs thought to be influential to health behaviors in general. TDF does not function as a theory or a model. Although the TDF is primarily utilized in an implementation context, it can be thought about as providing formal bounds on the range of known determinants of health behaviors and provide a structure for developing interventions (Michie et al., 2005; Cane, O’Connor, \& Michie, 2012; Atkins et al., 2017). Similar to the bounding principles in ecology, the TDF is applicable across a broad range of health behaviors and settings. It is an overarching conceptual device that constituent frameworks or models can be nested within (Atkins et al., 2017). The processes that have been built around a catalog of constructs create an operational framework (Atkins et al., 2017). In this framework, choices about behavioral outcomes and target mediators of intervention are driven by empirical justifications rather than deductive consequences of a particular theory (Atkins et al., 2017).

Other HP researchers have recommended the use of alternative approaches to framing based on the view that health behavior is part of a CAS with large numbers of diffuse, reciprocal, 
and non-linear influences that are not amenable to being mapped to the type of theory presented in Table 1. Bilodeau and Potvin (2018) outline how Actor-Network Theory can provide a way to structure HP research without setting out with a causal model. Van Beurden et al. (2013) lean on complexity theory to motivate the use of the Cynefin Framework. This framework provides guides based on the complexity and structure of the system under study for instituting, monitoring, and adapting interventions. These may act much more like the principles outlined in Jørgensen's ELT. The Cynefin Framework can be viewed as a general cognitive device in which constituent cognitive devices are nested.

\section{Paratheoretical Framing}

Important questions and approaches to hypothesis generation can occur without theory (Table 2; Dochtermann \& Jenkins, 2011). Although explicit prescription of abductive scientific approaches is uncommon in ecology, some ecologists have presented the view that some model building should be iterative and include abductive processes (Burnham \& Anderson, 2003;

Burnham, Anderson, \& Huyvaert, 2011). It is often the case that behavior researchers can structure sets of alternative tentative competing hypotheses based on empirical observations even in the absence of a hypothetico-deductive theory. Predictions from the hypotheses can be developed and empirically evaluated, which allows for the most likely hypothesis to be identified. Accordingly, there have been sporadic calls for greater acceptance of abductive research programs in the behavioral sciences (Griffin, 2006; Haig, 2005; Muthukrishna \& Henrich, 2019). If these alternative processes for framing HP research are not viewed as acceptable by reviewers, some HP researchers may patch together disparate and distant conceptual devices to be invoked as a justification for hypotheses or interpretations. This risks misleading readers regarding the authentic conceptual underpinnings of the research and the relevancy of the empirical findings to these distant theories. 
We suggest an alternative that can be described as paratheoretical inquiry. This approach is exploratory, integrative, and can be abductive. A paratheoretical process incorporates empirical observation and modeling through the iterative development of explanations. Importantly, it does not require theory to operate, yet connects to theory when opportunities for material contributions to theoretical development arise.

Individual steps in paratheoretical processes can take various forms. Consider efforts to address cigarette smoking in the United States. Substantial reduction in smoking in some countries has been considered a prominent public health success (Farrelly et al., 2017; Gilpin, Messer, White, \& Pierce, 2006). The success has been attributed to the implementation of MPOWER framework components (Farrelly et al., 2017), which is a multi-scale set of intervention modes and targets. As a whole, the interventions are not motivated by a theory. Two of the interventions are at the policy level. They limit product placement in retail establishments and increase taxes on cigarettes. These interventions (and their specific mechanisms) do not easily match up with the commonly cataloged conceptual devices used in HP.

Prohibition of cigarette displays in retail establishments is not an intervention that clearly falls out of the common health behavior conceptual devices. How do displays impact behavior? Smoking-related cues are capable of producing substantial increases in nicotine craving (Shiffman et al., 2013; Carpenter et al., 2014; Engelmann et al., 2012; Kim, Nonemaker, \& Farrelly, 2014). Cuereactivity investigations have provided important conceptual and practical advancement of the study of substance use. Presumably, lessons from this research could be useful to theoretical development for HP, and behavioral sciences more generally, through several modes. Cue-reactivity could be directly incorporated into extensions and modifications of current health behavior models. This has begun. West (2017) initiated a model that outlines the factors and their stage of influence 
during the progression and cessation of smoking behavior; cue-reactivity is included as a factor influencing cessation. West et al.'s work can catalyze investigations into the relative and contingent role of cue-reactivity at various stages of cigarette involvement. That body of work could then grow to support greater specification of the relationships among constructs (West et al., 2019; Meehl, 1990).

Paratheoretical postures can place research findings into the context of a broader understanding of health behaviors without a formal theory or even a conceptual device. The findings can also be used to structure and parameterize models used in the framing of subsequent research. Those models need not feed into a theory but can where the opportunity arises.

\section{Incorporating Alternative Approaches}

In summary, ecology and HP face similar challenges. Both are sparsely covered by ingrained theories. Both have histories of internal factions advocating for theory. A consequence of the heterogeneous complex systems that both investigate is the difficulty in obtaining powerful, sleek predictive cognitive devices. Theory is often identified as the device pivotal for achieving desired prediction and control in both fields. Further, both have a history of theory being considered too disconnected from practice. Although they have shared challenges, the fields now hold somewhat different postures toward theory. Ecology recognizes the ramifications of complexity theory and the importance of discriminating between models and theory. Much of HP continues to treat models and theory as functionally equivalent and operate with cognitive devices that do not reflect the complexities of the systems under study.

Ecology's theoretical work has been focused on constructing and analyzing models.

Ecologists understand that all models are wrong, and some have no proximal relevance to empirical reality. It would be malpractice for practitioners to use some models as a basis of their interventions 
in ecology. On the other hand, ingrained theory can be treated as adequately correct and the superior option for constructing interventions. Although some blurring has occurred, ecologists recognize the distinction between theory and models. In ecology, there is a strong recognition that models vary in their structure and utility and that their predictive capacities vary widely. HP has taken a different route in its relationship to theoretical investigations. Health behavior researchers have not consistently discriminated between theories and models (Bartholomew \& Mullen, 2011; Lippke \& Ziegelmann, 2008; Nilsen, 2015). Recommendations to use theory are commonly devoid of clarifications about the type or status of the cognitive device to be used. It leaves the field vulnerable to the belief that any cognitive device can be used interchangeably or in ad hoc combinations and still have met the field's expectation for leveraging theory.

If HP researchers choose to follow ecologists, a first step would be the expansion of their conceptual and lexical approach to theory. This step is likely to result in the acceptance that strong theory may be elusive and unnecessary for progress in HP. HP is pre-positioned to strengthen its commitment to abductive approaches. Rothman's suggestion for iterating HP relevant models through specification, application, evaluation, and refinement to obtain adequate models is feasible (Homer, 1996; Rothman, 2004). Lexical expansion, in combination with a disciplinary focus on modeling, will help resolve discrepancies between expectations and outcomes from the use of cognitive devices in HP. Closing this gap may reduce the propensity for practitioner skepticism and bring practitioners into the fold, as their role should be fundamental to adaptive model building. A combination of bounding principles and adaptive model building in paratheoretical research settings would be useful in guiding research in both established and expanding areas of inquiry. 


\section{References}

Aad, G., Abajyan, T., Abbott, B., Abdallah, J., Khalek, S. A., Abdelalim, A. A. et al. (2012).

Observation of a new particle in the search for the standard model higgs boson with the ATLAS detector at the LHC. Physics Letters B, 716(1), 1-29.

Akçakaya, H. R., Franklin, J., Syphard, A. D., \& Stephenson, J. R. (2005). Viability of Bell's sage sparrow (Amphispiza belli ssp. belli): altered fire regimes. Ecological Applications, 15(2), 521 531.

Albada, A., Ausems, M., Bensing, J. M., \& van Dulmen, S. (2009). Tailored information about cancer risk and screening: a systematic review. Patient Education and Counseling, 77(2), 155171.

Allen, T. F. H., \& Starr, T. B. (2017). Hierarchy. Chicago: University of Chicago Press.

Ashby, N. (2003). Relativity in the Global Positioning System. Living Rev Relativ, 6(1), 1.

Atkins, L., Francis, J., Islam, R., O'Connor, D., Patey, A., Ivers, N. et al. (2017). A guide to using the Theoretical Domains Framework of behaviour change to investigate implementation problems. Implementation Science, 12(1), 77.

Bartholome, L. K., Markham, C. M., Ruiter, R. A. C., Fernández, M. E., Kok, G., \& Parcel, G. S. (2016). Planning health promotion programs: an intervention mapping approach. John Wiley \& Sons.

Bartholomew, L. K., \& Mullen, P. D. (2011). Five roles for using theory and evidence in the design and testing of behavior change interventions. Journal of Public Health Dentistry, 71, S20-S33.

Beamish, R. J., \& Rothschild, B. J. (2009). The future of fisheries science in North America (31). Springer Science \& Business Media.

Bilodeau, A., \& Potvin, L. (2018). Unpacking complexity in public health interventions with the Actor-Network Theory. Health Promot Int, 33(1), 173-181.

Boniolo, G. (2007). On Scientific Representations: From Kant to a New Philosophy of Science. Springer.

Boonstra, R., Krebs, C. J., \& Stenseth, N. C. (1998). Population cycles in small mammals: the problem of explaining the low phase. Ecology, 79(5), 1479-1488.

Braysher, M., Buckmaster, T., Saunders, G., \& Krebs, C. J. (2012). Principles underpinning best practice management of the damage due to pests in Australia. In 25(25) (pp. 300-307). Monterey, California: University of California, Davis.

Brug, J., Oenema, A., \& Ferreira, I. (2005). Theory, evidence and Intervention Mapping to improve behavior nutrition and physical activity interventions. Int J Behav Nutr Phys Act, 2(1), 2.

Burkholder, G. J., Cox, K. A., Crawford, L. M., \& Hitchcock, J. H. (2019). Research Design and Methods. Thousand Oaks, CA: SAGE Publications.

Burnham, K. P., \& Anderson, D. R. (2003). Model selection and multimodel inference: a practical information-theoretic approach. New York: Springer Science \& Business Media.

Burnham, K. P., Anderson, D. R., \& Huyvaert, K. P. (2011). AIC model selection and multimodel inference in behavioral ecology: some background, observations, and comparisons. Behavioral Ecology and Sociobiology, 65(1), 23-35.

Campbell, M., Fitzpatrick, R., Haines, A., Kinmonth, A. L., Sandercock, P., Spiegelhalter, D. et al. (2000). Framework for design and evaluation of complex interventions to improve health. British Medical Journal, 321(7262), 694-696.

Cane, J., O'Connor, D., \& Michie, S. (2012). Validation of the theoretical domains framework for use in behaviour change and implementation research. Implementation Science, 7(1), 37. 
Carpenter, M. J., Saladin, M. E., Larowe, S. D., McClure, E. A., Simonian, S., Upadhyaya, H. P. et al. (2014). Craving, cue reactivity, and stimulus control among early-stage young smokers: effects of smoking intensity and gender. Nicotine Tob Res, 16(2), 208-215.

Chesson, P. L., \& Case, T. J. (1986). Overview: nonequilibrium community theories: chance, variability, history. In J. Diamond \& T. J. Case (Eds.), Community Ecology (pp. 229-239). New York: Harper and Row.

Chitty, D. (1996). Do Lemmings Commit Suicide: Beautiful Hypotheses and Ugly Facts. Oxford: Oxford University Press.

Christiansen, F. B., \& Fenchel, T. M. (2012). Theories of Populations in Biological Communities. Springer Science \& Business Media.

Collie, J. S., Richardson, K., \& Steele, J. H. (2004). Regime shifts: can ecological theory illuminate the mechanisms. Progress in Oceanography, 60(2-4), 281-302.

Converse, S. J., \& Moore, C. T. (2013). Demographics of reintroduced populations: estimation, modeling, and decision analysis. Journal of Wildlife Management, 77(6), 1081-1093.

Crosby, R. A., Kegler, M. C., \& DiClemente, R. J. (2009). Theory in health promotion practice and research. In Emerging Theories in Health Promotion Practice and Research (pp. 3-18). San Francisco: Jossey-Bass.

Cummins, K., Pitpitan, E. V., Reed, M. B., zuniga, m. 1., \& Brown, S. A. (2020, August 22). Potential Explanations for the Limited Empirical Evidence in Support of Theory in Health Promotion. https://doi.org/10.31219/osf.io/976ex

Datta, J., \& Petticrew, M. (2013). Challenges to evaluating complex interventions: a content analysis of published papers. BMC Public Health, 13, 568.

Dayton, P. (1980). This week's citation classic. Current Contents, 32, 156.

Dochtermann, N. A., \& Jenkins, S. H. (2011). Developing multiple hypotheses in behavioral ecology. Behavioral Ecology and Sociobiology, 65(1), 37-45.

Engelmann, J. M., Versace, F., Robinson, J. D., Minnix, J. A., Lam, C. Y., Cui, Y. et al. (2012). Neural substrates of smoking cue reactivity: a meta-analysis of fMRI studies. Neuroimage, 60(1), 252-262.

Event Horizon Telescope Collaboration, Akiyama, K., Alberdi, A., Alef, W., Asada, K., Azulay, R. et al. (2019). First M87 event horizon telescope results. I. the shadow of the supermassive black hole. The Astrophysical Journal, 875(1), L1.

Farrelly, M. C., Chaloupka, F. J., Berg, C. J., Emery, S. L., Henriksen, L., Ling, P. et al. (2017). Taking stock of tobacco control program and policy science and impact in the United States. Journal of addictive behaviors and therapy, 1(2).

Flyvbjerg, B. (2001). Making social science matter: Why social inquiry fails and how it can succeed again. Cambridge, UK: Cambridge University Press.

Frigg, R., \& Hartmann, S. (2006). Scientific Models. In S. Sarkar \& J. Pfeifer (Eds.), The Philosophy of Science: An Encyclopedia (pp. 740-749). London: Routledge.

Gigerenzer, G. (2011). Surrogates for theory. APS observer, 22(2).

Gilpin, E. A., Messer, K., White, M. M., \& Pierce, J. P. (2006). What contributed to the major decline in per capita cigarette consumption during California's comprehensive tobacco control programme. Tobacco Control, 15(4), 308-316.

Glanz, K., \& Bishop, D. B. (2010). The role of behavioral science theory in development and implementation of public health interventions. Annual Review of Public Health, 31, 399-418.

Glanz, K., Rimer, B. K., \& Viswanath, K. (2015). Health Behavior: Theory, Research, and Practice (Fifth Edition ed.). San Fransisco: Jossey-Bass.

Godfrey-Smith, P. (2009). Theory and Reality. University of Chicago Press.

Gorelick, R. (2011). What is theory? Ideas in Ecology and Evolution, 4, 1-10. 
Green, L. W. (2006). Public health asks of systems science: to advance our evidence-based practice, can you help us get more practice-based evidence. American Journal of Public Health, 96(3), 406-409.

Griffin, W. A. (2006). Agent-based modeling for the theoretical biologist. Biological Theory, 1(4), 404-409.

Grime, J. P. (2007). Plant strategy theories: a comment on Craine (2005). Journal of Ecology, 95(2), 227-230.

Hagger, M. S., \& Weed, M. (2019). DEBATE: Do interventions based on behavioral theory work in the real world. Int J Behav Nutr Phys Act, 16(1), 36.

Haig, B. D. (2005). An abductive theory of scientific method. Psychological Methods, 10(4), 371388.

Haller, B. C. (2014). Theoretical and empirical perspectives in ecology and evolution: a survey. BioScience, 64(10), 907-916.

Harper, J. L. (1980). Plant demography and ecological theory. Oikos, 35(2), 244-253.

Harré, R. (2004). Modeling: Gateway to the Unknown: a Work (1). New York: Elsevier.

Hilborn, R., \& Ovando, D. (2014). Reflections on the success of traditional fisheries management. ICES Journal of Marine Science, 71(5), 1040-1046.

Hodges, K. E. (2008). Defining the problem: terminology and progress in ecology. Frontiers in Ecology and the Environment, 6(1), 35-42.

Homer, J. (1996). Why we iterate: scientific modeling in theory and practice. Systems Dynamics Review, 12(1), 1-19.

Homer, J., \& Hirsch, S. (2006). System dynamics modeling for public health: background and opportunities. American Journal of Public Health, 96(3), 452-458.

Hovell, M. F., Wahlgren, D. R., \& Adams, M. A. (2009). The logical and empirical basis for the behavioral ecological model. Emerging Theories in Health Promotion Practice and Research, 2, 347-385.

Cody, M., \& Diamond, J. (Eds.). (1975). Variations on a theme by Robert MacArthur. Harvard University Press.

Imenda, S. (2014). Is there a conceptual difference between theoretical and conceptual frameworks. Journal of Social Sciences, 38(2), 185-195.

Jørgensen, S. E., Fath, B. D., Bastianoni, S., Marques, J. C., Muller, F., Nielsen, S. N. et al. (2011). $A$ New Ecology: Systems Perspective. New York: Elsevier.

Keshavarz Mohammadi, N. (2019). One step back toward the future of health promotion: complexity-informed health promotion. Health Promotion International, 34(4), 635-639.

Kim, A. E., Nonemaker, J. M., \& Farrelly, M. C. (2014). Influence of Point-of-Sale Tobacco Displays and Graphic Health Warning Signs on Adults: Evidence from a Virtual Store Experimental Study. American Journal of Public Health, 104(5), 889-895.

Kolasa, J. (2011). Theory makes ecology evolve. In S. Scheiner \& M. Willig (Eds.), The Theory of Ecology (pp. 21-50). Chicago: University of Chicago Press.

Krebs, C. J. (2017). 10 possible limitations of current ecological theory. Australian Zoologist, 38(3), 267-271.

Krieger, N., \& Zierler, S. (1996). What explains the public's health?: a call for epidemiologic theory. Epidemiology, 107-109.

Lawson, D. M., Regan, H. M., Zedler, P. H., \& Franklin, J. (2012). Cumulative effects of land use, altered fire regime and climate change on persistence of ceanothus verrucosus, a rare, firedependent plant species. Global Change Biology, 18(9), 2980-2980.

Lehman, C. L., \& Tilman, D. (1997). Competition in spatial habitats. Spatial Ecology: The Role of Space in Population Dynamics and Interspecific Interactions, 185-203. 
Levin, S. A. (1992). The problem of pattern and scale in ecology: the Robert H. MacArthur award lecture. Ecology, 73(6), 1943-1967.

Levin, S. A. (1998). Ecosystems and the biosphere as complex adaptive systems. Ecosystems, 1(5), 431-436.

Levin, S. A. (1999). Towards a science of ecological management. Conservation Ecology, 3(2).

Levin, S. A. (2005). Self-organization and the emergence of complexity in ecological systems. Bioscience, 55(12), 1075-1079.

Levins, R. (1966). The strategy of model building in population biology. American Scientist, 54(4), 421-431.

Leviton, L. C. (2017). Generalizing about public health interventions: a mixed-methods approach to external validity. Annual Review of Public Health, 38, 371-391.

Levy, D. T., Bauer, J. E., \& Lee, H. R. (2006). Simulation modeling and tobacco control: creating more robust public health policies. American Journal of Public Health, 96(3), 494-498.

Lewis, R. W. (1982). Theories, structure, teaching, and learning. BioScience, 32(9), 734-737.

Lippke, S., \& Ziegelmann, J. P. (2008). Theory-based health behavior change: developing, testing, and applying theories for evidence-based interventions. Applied Psychology, 57(4), 698-716.

Lock, M., Post, D., Dollman, J., \& Parfitt, G. (2020). Efficacy of theory-informed workplace physical activity interventions: a systematic literature review with meta-analyses. Health Psychol Rev, 125.

MacArthur, R. (1962). Growth and regulation of animal populations. Ecology, 43(3), 579.

Margalef, R. (1963). On certain unifying principles in ecology. The American Naturalist, 97(897), 357-374.

Maris, V., Huneman, P., Coreau, A., Kéfi, S., Pradel, R., \& Devictor, V. (2018). Prediction in ecology: promises, obstacles and clarifications. Oikos, 127(2), 171-183.

Marquet, P. A., Allen, A. P., Brown, J. H., Dunne, J. A., Enquist, B. J., Gillooly, J. F. et al. (2014). On theory in ecology. BioScience, 64(8), 701-710.

May, R. M. (1976). Simple mathematical models with very complicated dynamics. Nature, $261(5560), 459$.

May, R. M. (1981). The role of theory in ecology. American Zoologist, 21(4), 903-910.

May, R. M., \& Oster, G. F. (1976). Bifurcations and dynamic complexity in simple ecological models. The American Naturalist, 110(974), 573-599.

McIntosh, R. P. (1980). The background and some current problems of theoretical ecology. Synthese, 43(2), 195-255.

McIntosh, R. P. (1986). The Background of Ecology. Cambridge University Press.

McMullin, E. (1976). The fertility of theory and the unit for appraisal in science. In Essays in Memory of Imre Lakatos (pp. 395-432). New York: Springer.

Meehl, P. E. (1990). Appraising and amending theories: the strategy of lakatosian defense and two principles that warrant it. Psychological Inquiry, 1(2), 108-141.

Michie, S., Johnston, M., Abraham, C., Lawton, R., Parker, D., Walker, A. et al. (2005). Making psychological theory useful for implementing evidence based practice: a consensus approach. Qual Saf Health Care, 14(1), 26-33.

Michie, S. F., West, R., Campbell, R., Brown, J., \& Gainforth, H. (2014). ABC of behaviour change theories. Silverback Publishing.

Michie, S., Johnston, M., Francis, J., Hardeman, W., \& Eccles, M. (2008). From theory to intervention: mapping theoretically derived behavioural determinants to behaviour change techniques. Applied Psychology, 57(4), 660-680.

Michie, S., \& Prestwich, A. (2010). Are interventions theory-based? development of a theory coding scheme. Health Psychology, 29(1), 1. 
Mulyukova, E., \& Bercovici, D. (2019). The Generation of Plate Tectonics From Grains to Global Scales: A Brief Review. Tectonics, 38(12), 4058-4076.

Murray, B. G. (2001). Are ecological and evolutionary theories scientific. Biological Reviews, 76(2), 255-289.

Muthukrishna, M., \& Henrich, J. (2019). A problem in theory. Nature Human Behaviour.

National Research Council. (1986). Ecological knowledge and environmental problem-solving: concepts and case studies. Washington, DC: National Academies Press.

Nigg, C. R., Allegrante, J. P., \& Ory, M. (2002). Theory-comparison and multiple-behavior research: common themes advancing health behavior research. Health Education Research, 17, 670-679.

Nilsen, P. (2015). Making sense of implementation theories, models and frameworks. Implementation Science, 10, 53.

Noar, S. M., Benac, C. N., \& Harris, M. S. (2007). Does tailoring matter? meta-analytic review of tailored print health behavior change interventions. Psychological Bulletin, 133(4), 673.

Noar, S. M., \& Zimmerman, R. S. (2005). Health behavior theory and cumulative knowledge regarding health behaviors: are we moving in the right direction. Health Education Research, 20(3), 275-290.

Oster, G. (1981). Predicting populations. American Zoologist, 21(4), 831-844.

Painter, J. E., Borba, C. P., Hynes, M., Mays, D., \& Glanz, K. (2008). The use of theory in health behavior research from 2000 to 2005: a systematic review. Ann Behav Med, 35(3), 358-362.

Pickett, S. T. A., Kolasa, J., \& Jones, C. G. (2010). Ecological understanding: the nature of theory and the theory of nature. Elsevier.

Prestwich, A., Sniehotta, F. F., Whittington, C., Dombrowski, S. U., Rogers, L., \& Michie, S. (2014). Does theory influence the effectiveness of health behavior interventions? meta-analysis. Health Psychology, 33(5), 465.

Railsback, S. F. (2001). Concepts from complex adaptive systems as a framework for individualbased modelling. Ecological modelling, 139(1), 47-62.

Reback, C. J., Fletcher, J. B., Shoptaw, S., \& Mansergh, G. (2015). Exposure to theory-driven text messages is associated with HIV risk reduction among methamphetamine-using men who have sex with men. AIDS and Behavior, 19(2), 130-141.

Renshaw, E. (1993). Modelling biological populations in space and time. Cambridge, UK: Cambridge University Press.

Resnicow, K., \& Page, S. E. (2008). Embracing chaos and complexity: a quantum change for public health. American journal of public health, 98(8), 1382-1389.

Romesburg, H. C. (1981). Wildlife science: gaining reliable knowledge. The Journal of Wildlife Management, 293-313.

Rothman, A. J. (2004). "Is there nothing more practical than a good theory?": Why innovations and advances in health behavior change will arise if interventions are used to test and refine theory. International Journal of Behavioral Nutrition and Physical Activity, 1, 11.

Ryan, J. G., Ludwig, J. A., \& Mcalpine, C. A. (2007). Complex adaptive landscapes (CAL): A conceptual framework of multi-functional, non-linear ecohydrological feedback systems. Ecological Complexity, 4(3), 113-127.

Sagoff, M. (2016). Are there general causal forces in ecology. Synthese.

Sallis, J. F., Owen, N., \& Fisher, E. (2015). Ecological models of health behavior. Health Behavior: Theory, Research, and Practice, 5, 43-64.

Scheiner, S. M. (2012). The multiple roles of theory: a reply to gorelick. Ideas in Ecology and Evolution, 5.

Scheiner, S. M. (2013). The ecological literature, an idea-free distribution. Ecology Letters, 16(12), 1421-1423. 
Scheiner, S. M., \& Willig, M. R. (2011a). A general theory of ecology. In The Theory of Ecology. Chicago: University of Chicago Press.

Scheiner, S. M., \& Willig, M. R. (2011b). The Theory of Ecology. Chicago: University of Chicago Press.

Scheiner, S. M., \& Willig, M. R. (2008). A general theory of ecology. Theoretical Ecology, 1, 21-28.

Schlueter, M., Mcallister, R. R. J., Arlinghaus, R., Bunnefeld, N., Eisenack, K., Hoelker, F. et al. (2012). New horizons for managing the environment: A review of coupled social-ecological systems modeling. Natural Resource Modeling, 25(1), 219-272.

Schnute, J. T., \& Richards, L. J. (2001). Use and abuse of fishery models. Canadian Journal of Fisheries and Aquatic Sciences.

Shiffman, S., Dunbar, M., Kirchner, T., Li, X., Tindle, H., Anderson, S. et al. (2013). Smoker reactivity to cues: effects on craving and on smoking behavior. J Abnorm Psychol, 122(1), 264280.

Shrader-Frechette, K. (2008). A companion to environmental philosophy. John Wiley \& Sons.

Slobodkin, L. B. (1965). On the present incompleteness of mathematical ecology. American Scientist, 53(3), 347-357.

Smit, F., Lokkerbol, J., Riper, H., Majo, C., Boon, B., \& Blankers, M. (2011). Modeling the costeffectiveness of health care systems for alcohol use disorders: how implementation of eHealth interventions improves cost-effectiveness. Journal of Medical Internet Research, 13(3), e56.

Smith, F. E. (1952). Experimental methods in population dynamics: a critique. Ecology, 33(4), 441450.

Smith, F. E. (1976). Ecology: progress and self-criticism. Science.

Staley, K. W. (2014). An Introduction to the Philosophy of Science. Cambridge, UK: Cambridge University Press.

Van Beurden, E. K., Kia, A. M., Zask, A., Dietrich, U., \& Rose, L. (2013). Making sense in a complex landscape: how the Cynefin Framework from Complex Adaptive Systems Theory can inform health promotion practice. Health Promot Int, 28(1), 73-83.

Wangersky, P. J. (1978). Lotka-Volterra population models. Annual Review of Ecology and Systematics, 9(1), 189-218.

Weisberg, M. (2007). Three kinds of idealization. The journal of Philosophy, 104(12), 639-659.

West, R. (2017). Tobacco smoking: Health impact, prevalence, correlates and interventions. Psychol Health, 32(8), 1018-1036.

West, R., Godinho, C. A., Bohlen, L. C., Carey, R. N., Hastings, J., Lefevre, C. E. et al. (2019). Development of a formal system for representing behaviour-change theories. Nat Hum Behav, 3(5), 526-536.

Yodzis, P. (1989). Introduction to Theoretical Ecology. San Fransisco: HarperCollins College Division.

Zheng, Y.-F. (2018). Fifty years of plate tectonics. National Science Review, 5(2), 119-119. 
Theory in Health Promotion

\section{Table 1. Provisional taxonomy of scientific theory}

\begin{tabular}{|c|c|}
\hline Conceptual Device & Description \\
\hline Archetypal Theory & $\begin{array}{l}\text { Predictive and explanatory scientific theory with properties presented in } \\
\text { Cummins et al. (2020) that are consistent with those attributed to theories in } \\
\text { the physical sciences. Physics provides examples of strong theory with salient } \\
\text { novel predictions. Examples include the Higg's boson and the recent black hole } \\
\text { measurements (Aad et al., 2012; Event Horizon Telescope Collaboration et al., } \\
\text { 2019). }\end{array}$ \\
\hline Emerging Theory & $\begin{array}{l}\text { Theory that has gathered empirical support as a potential replacement for prior } \\
\text { Theory or addresses a domain not previously covered by theory, however, the } \\
\text { body of evidence is not yet conclusive. }\end{array}$ \\
\hline Proposed Theory & $\begin{array}{l}\text { Theory that has been merely proposed or evolved with little work aimed at } \\
\text { elucidating and challenging its empirical consequences. It should only be } \\
\text { considered an incipient or prospective explanation. Scientific skepticism would } \\
\text { dictate that it not be adopted for application out of hand, even if it addresses a } \\
\text { gap in the theoretical landscape. }\end{array}$ \\
\hline Ingrained Theory & $\begin{array}{l}\text { Substantiated Theory so firmly accepted by the field it is considered a working } \\
\text { fact that embedded into in the field's common knowledge base (Lewis, 1982). } \\
\text { These should have surmounted strong empirical challenges and hold high } \\
\text { verisimilitude, to the extent that it is accepted as the exclusively correct } \\
\text { explanation (McMullin, 1976). Anomalies (Staley, 2014) and viable } \\
\text { alternative theories should be absent. }\end{array}$ \\
\hline Tarnished Theory & $\begin{array}{l}\text { An otherwise ingrained theory that has not been discarded, but is at risk of } \\
\text { degenerating because of new anomalies or challenges posed by a new } \\
\text { competing theory. Outright rejection may not be warranted, but its prior } \\
\text { verisimilitude is in question. }\end{array}$ \\
\hline Constituent Theory & $\begin{array}{l}\text { Theory that is constrained by a set of principles that apply more broadly than } \\
\text { the Theory itself (Scheiner \& Willig, 2008). }\end{array}$ \\
\hline Organizing Framework & $\begin{array}{l}\text { Conceptual device that might not be predictive, explanatory, or refutable as a } \\
\text { whole, that makes it critical to distinguish from other conceptual devices. It is } \\
\text { any device used to structure investigations, interpretations, and the } \\
\text { communication of assumptions and findings. It may include some explanation } \\
\text { regarding the patterns observed, but is materially deficient in diagnostic aspects } \\
\text { of theory (Flyvbjerg, 2001). This CD includes conceptual (Imenda, 2014; } \\
\text { Burkholder, Cox, Crawford, \& Hitchcock, 2019), theoretical (Pickett, Kolasa, \& } \\
\text { Jones, 2010), or determinant (Nilsen, 2015) frameworks. }\end{array}$ \\
\hline
\end{tabular}




\section{Theory in Health Promotion}

Table 2. Complementary strategies for structuring HP research in the absence of Theory.

\begin{tabular}{|c|c|c|c|}
\hline Process Domain & Feature & Approach & Notes on Related Literature \\
\hline \multirow[t]{2}{*}{ Lexical evolution } & $\begin{array}{c}\text { Differentiation among } \\
\text { conceptual devices }\end{array}$ & $\begin{array}{l}\text { Extend the field's vocabulary to } \\
\text { increase the salience of the } \\
\text { different qualities of theories, } \\
\text { models, and frameworks without } \\
\text { attempting to reform terms } \\
\text { currently in use. }\end{array}$ & $\begin{array}{l}\text { Hodges (2008) recognized that attempts to } \\
\text { reform current terminology require consensus } \\
\text { and current users to adopt new norms, while } \\
\text { future researchers would need to avoid adopting } \\
\text { applications found in the legacy literature } \\
\text { (Hodges, 2008). Expanding the vocabulary avoids } \\
\text { this and facilitates conceptual clarity. }\end{array}$ \\
\hline & $\begin{array}{l}\text { Identification and } \\
\text { declaration of theory } \\
\text { status }\end{array}$ & $\begin{array}{l}\text { Develop a nomenclature to } \\
\text { facilitate the consistent } \\
\text { description of Theory status. }\end{array}$ & $\begin{array}{l}\text { Recommendations about use of Theory based on } \\
\text { Theory status may improve expectations related } \\
\text { to Theory. Both Kolasa (2011) and Pickett (2010) } \\
\text { outlined the importance of evidentiary status in } \\
\text { use of Theory. }\end{array}$ \\
\hline $\begin{array}{l}\text { Theory } \\
\text { development }\end{array}$ & Bounding principles & $\begin{array}{l}\text { Develop suites of bounding } \\
\text { principles that can guide the } \\
\text { conceptual development of } \\
\text { models and constituent Theories }\end{array}$ & $\begin{array}{l}\text { Jørgensen et al. (2011) and Scheiner and Willig } \\
\text { (2008) present exemplars of bounding principles } \\
\text { that can help guide research in sub-disciplines } \\
\text { where Theory is sparse. }\end{array}$ \\
\hline \multirow{3}{*}{ Research framing } & $\begin{array}{l}\text { Phenomenological } \\
\text { modeling }\end{array}$ & $\begin{array}{l}\text { When Theory is unavailable, build } \\
\text { and use models which are } \\
\text { untethered from Theory }\end{array}$ & $\begin{array}{l}\text { Boniolo (2007) provided a cogent description of } \\
\text { the role of scientific modeling in the absence of } \\
\text { Theory. }\end{array}$ \\
\hline & Abductive inference & $\begin{array}{l}\text { Allow for some research } \\
\text { hypotheses to be created from } \\
\text { the creative integration of } \\
\text { observations and analysis. }\end{array}$ & $\begin{array}{l}\text { Haig (2005) described research that iterates } \\
\text { through best guesses given the current body of } \\
\text { knowledge and updating assessments as new } \\
\text { evidence emerges (Haig, 2005). }\end{array}$ \\
\hline & $\begin{array}{l}\text { Paratheoretical } \\
\text { programs }\end{array}$ & $\begin{array}{l}\text { Allow for some important } \\
\text { research questions to be } \\
\text { answered in the absence of } \\
\text { connections to hypothetic- } \\
\quad \text { deductive Theory }\end{array}$ & $\begin{array}{l}\text { Where Engrained Theory is unavailable to apply } \\
\text { to an important research question, the } \\
\text { application of sound scientific methodology can } \\
\text { still provide valuable answers and potentially } \\
\text { inform future Theory development. }\end{array}$ \\
\hline
\end{tabular}




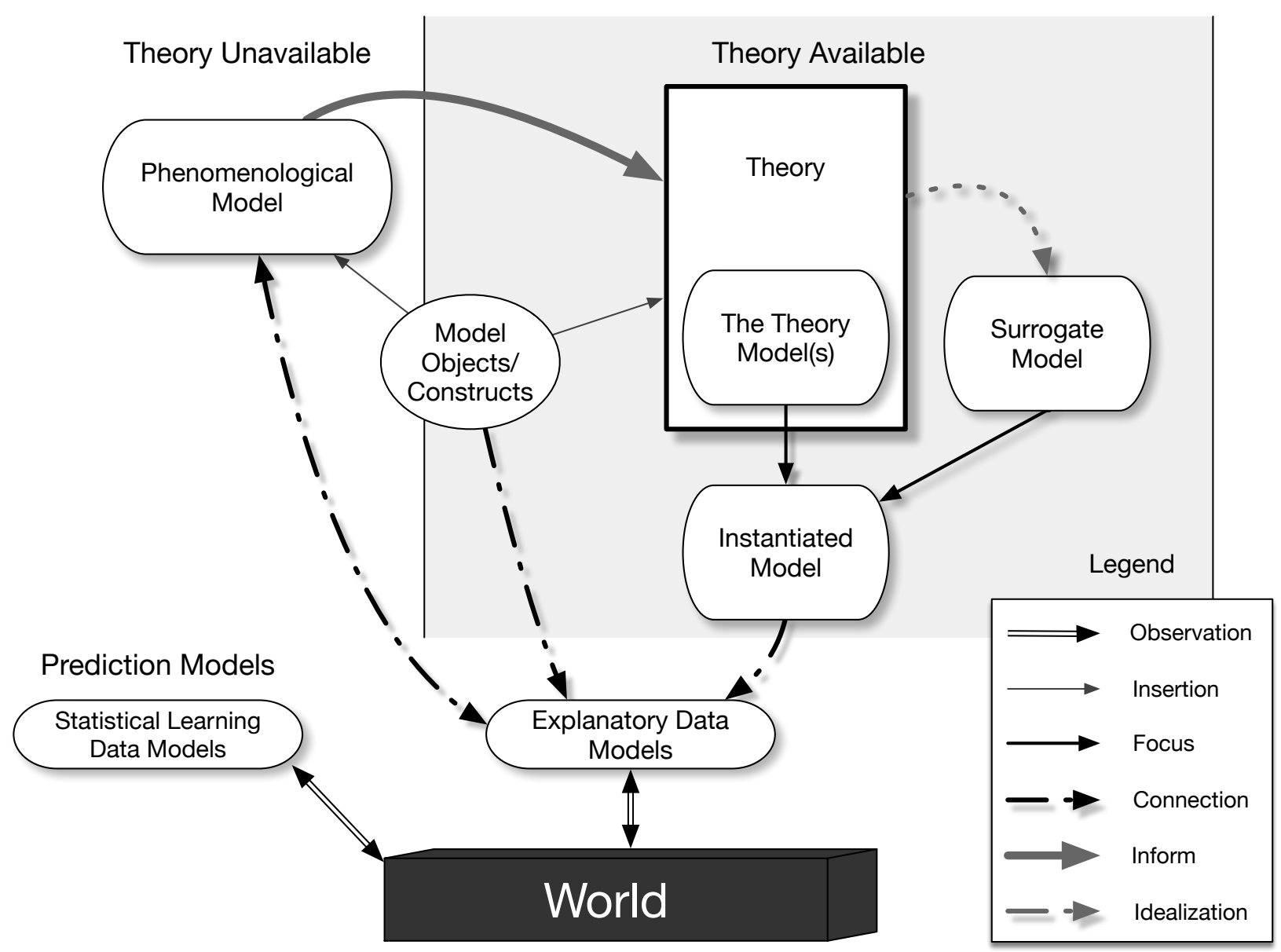

Figure 1. The relationship between Theory, model types, and reality. Necessary aspects of a Theory needed for a particular solution are collected and instantiated via focusing, where an instantiated model is created so it is useful in the context of the specific problem (Boniolo, 2007). If a Theory's mechanisms map to intractable models, convenient models (surrogate models) that do not hold the structure of the Theory's mechanism may be substituted through idealization (Weisberg, 2007). Measurement models for the entities operating in the CDs are the objects (i.e., constructs) inserted into relational models and Theory. Phenomenological models are constructed from various sources of knowledge in the absence of Theory (Frigg \& Hartmann, 2006). These can inform Theory development. All models can be directly connected to empirical observation through data models. This figure was adapted from Boniolo (Boniolo, 2007). 